\title{
Sobre o processo de edição dos textos jesuítas nas cartas da América portuguesa no século xvı
}

\section{Adriana Gabriel Cerello}

Resumo A partir da obra Cartas dos primeiros jesuitas do Brasil (1954), organizada por Serafim Leite, este artigo buscará estudar alguns aspectos do processo de produção livresca do século XVI, em particular as condições de redação e edição dos manuscritos dentro e fora do ambiente da Igreja Católica e a circulação na Metrópole e na Colônia. Partindo da observação de um momento histórico em que a maneira de ler, escrever e difundir os textos sofreu mudanças profundas, pretende-se reconstruir parte da história da cultura material do livro no século xvi. Palavras-chave literatura brasileira; Jesuítas; História do livro; cartas.

Abstract Considering the work Cartas dos primeiros jesuitas do Brasil (1954), organized by Serafim Leite, this article is an attempt at studying some aspects of book production process in the sixteenth century, particularly concerning writing conditions, publishing and circulation of manuscripts (inside and outside Catholic Church boundaries) as well as distribution and trading in the Metropolis and Colony. Taking into account that texts underwent considerable changes, we intend to recount part of history regarding material culture of book in the sixteenth. Keywords Brazilian literature; Jesuits; correspondence; book history; letters. 
Pode-se dizer que as cartas dos jesuítas produzidas no primeiro século da colonização tratam basicamente da catequização e da escravização do índio, da moralização do colono, da organização e da distribuição de funções entre os padres, assim como da ocupação e do governo do território e da exploração econômica das terras americanas. Não são textos naturais, visto que produzidos numa determinada época, com base em usos específicos, fazendo-se necessária a reconstrução de alguns dos condicionamentos históricos, literários, institucionais, linguísticos e materiais da produção deles.

Os documentos jesuíticos e as letras coloniais A obra Cartas dos primeiros jesuitas no Brasil, publicada em 1954 em 3 volumes, traz mais de duzentos documentos que abarcam o período de 1538 a 1563. Foram escritos na América e na Europa por padres da Companhia de Jesus e por personalidades de fora dela e encontram-se hoje fundamentalmente em arquivos e bibliotecas de Roma, Lisboa, Évora, Madri e do Rio de Janeiro. O levantamento, a organização e, principalmente, o estudo desse corpus são fruto do trabalho intelectual do padre jesuíta português Serafim Leite. Este alega ter procurado sempre alcançar os originais manuscritos, que no século XVI passavam pelo processo de cópia e tradução para diversas línguas e, ainda, por emendas, revisões e censuras antes de serem impressos.

A princípio, é preciso lembrar que esse trabalho de edição de cartas decorreu da História da Companhia de Jesus no Brasil, obra encomendada pela Companhia de Jesus ao padre Serafim Leite dentro da tradição historiográfica da Ordem, tão antiga quanto sua fundação. Assim, ao levar em conta a voz institucional do organizador, em situação de total simpatia por seu objeto, depreende-se que a disposição e o recorte que faz da documentação jesuítica não são objetivos ou independentes de teorias e interpretações de seu próprio tempo e lugar, e assim também não o são os fatos por ele inventariados.

Além disso, os documentos usados por Serafim Leite são todos eles quase que exclusivos dos arquivos da Companhia de Jesus e a maioria continua de acesso bastante restrito. Esse fato leva a questionamentos quanto a seus critérios historiográficos, pois supõe o leitor aceitando sua tradução e interpretação como verídicas, já que únicas. Escassas são as vezes em que aparecem citadas em suas notas outras fontes, especialmente as discordantes das posições da Ordem jesuíta. 
Devido ainda ao uso exclusivo dos documentos, Serafim Leite e outros jesuítas em vários períodos são responsáveis pela perpetuação de uma imagem jesuítica construída para justificar a Ordem ao longo dos diversos momentos da história. Por meio da manipulação textual, um caráter de "verdade histórica" dos textos dos jesuítas dos primeiros séculos passou a ser legitimado pelo critério da valorização dos mesmos como "documentos", como testemunhos "autênticos" e "verídicos" dos fatos históricos."

Há, sobretudo, a questão primeira que é o pressuposto da existência do Deus católico. Também Serafim Leite insere seu discurso (e suas interpretações) nessa premissa e cabe ao leitor lembrar que o Catolicismo é uma religião historicamente constituída.

Contudo, cabe olhar para essas letras por meio dos processos de invenção de seu tempo e não pelas leituras realizadas nos séculos posteriores. Assim, as letras do século Xvi merecem ser entendidas dentro de uma perspectiva ampla em que se detectam padrões duradouros de estabilidade das estruturas de publicação. Desse modo, é o caso de pensar as letras em sequências que vão além da cronológica e que descrevam uma continuidade dos temas e estilos ao longo dos tempos e através das obras. Tome-se, portanto, como pressuposto uma outra concepção das letras coloniais que são consideradas como parte de uma sociedade de Antigo Regime em que as interpretaçōes do homem são ibéricas e católicas, teológicopolíticas e metafísicas, e na qual não se encontram

as categorias iluministas e pós-iluministas quase sempre generalizadas transistoricamente como evidentes, caso da expressão psicológica da individualidade, da originalidade e dos direitos autorais que garantem a propriedade das obras e noções correlatas, como "plágio", "crítica", "negatividade", "ruptura estética", "autonomia política", "estética", "literatura", "autonomia estética", "psicologia" etc.

1 VILAR, Socorro de Fátima Pacífico. A invenção de uma escrita: Anchieta, os jesuitas e suas histórias. Porto Alegre: Ed. PUCRS, 2006, p. 92-3, conforme PÉCORA, Alcir. Teatro do Sacramento. São Paulo: Edusp/Editora da Unicamp, 1994.

2 HANSEN, João Adolfo. A civilização pela palavra. In: LOPES, Eliana Maria Teixeira (Org.). 500 anos de educação no Brasil. $2^{\text {a }}$ ed. Belo Horizonte: Autêntica, 2000, p. 34. 
Contrariamente ao experimentado na nossa sociedade de classes, o autor não é definido pelo ponto de vista da sua identidade nacional, nem como uma categoria psicológica; a obra não é um bem material passivel de troca econômica num mercado de bens culturais regulamentado juridicamente por direitos autorais, nem o leitor é alguém com direito de manifestar-se criticamente sobre essa obra, fazendo valer sua autonomia democrática.

As letras aqui são, primeiramente, inspiradas por Deus; quem as escreve é tão somente o instrumento para a transmissão da Palavra. São também consideradas parte de um "estilo" no qual os textos são construídos pelo uso de "lugares-comuns de tipos e situações" e que confiam à memória essas tópicas conhecidas da audiência, fazendo da sua repetição, comentário, desenvolvimento ou glosa um critério positivo de avaliação dos discursos. ${ }^{3}$

Pode-se dizer a partir daí que tanto os missivistas jesuítas em terras da Colônia quanto os europeus letrados que liam as cartas americanas dominavam os mesmos padrões retóricos de produção de textos; não havia, portanto, um desnível entre a produção letrada europeia e as letras concebidas na Colônia americana. Havia, sim, uma continuidade de um lado e de outro do Atlântico, mesmo porque devemos partir do pressuposto de que naquele momento não havia Brasil, mas somente o Império Português em que a Colônia se incluía como região subordinada. ${ }^{4}$ Esse pressuposto evita o anacronismo e alarga para além das fronteiras terrestres atuais do Brasil o espaço geográfico e administrativo da época. $\mathrm{O}$ intercâmbio de autores e textos seguia o mesmo padrāo.

As cartas dos jesuítas É possível afirmar que as cartas escritas pelos jesuítas obedeciam a critérios epistolográficos bem definidos, prescritos nas Constituiçōes, que regulavam o funcionamento da Companhia de Jesus. Apesar de a sua primeira edição datar apenas de 1558, já em 1547 Inácio de Loyola e seu secretário em Roma, Juan Alfonso de Polanco, determinaram que as missões passassem a enviar

3 Ibidem, p. 34.

4 NOVAIS, Fernando A. (Coord.) e SOUZA, Laura de Mello (Org.). História da vida privada no Brasil: cotidiano e vida privada na América portuguesa. Sāo Paulo: Companhia das Letras, 1997, p. 7-11.

254 • CERELLO, Adriana Gabriel. Sobre o processo de edição dos textos jesuítas... 
relatórios minuciosos para Roma. Assim, além de obedecerem às várias exigências da Ordem - difusão dos resultados da catequese, incentivo de vocações, controle do governo central sobre os membros dispersos e confirmação da identidade desses membros - , as cartas eram reguladas por prescrições rígidas, que distinguiam gêneros epistolares conforme as matérias tratadas e os destinatários.

A correspondência dos jesuítas do século XVI cumpre então a determinação do envio de relatórios, aplicando os dois gêneros de carta definidos na tradição da preceptiva epistolar: negocial (oficiais, com matéria argumentativa séria) e familiar ("particular", breves e claras). ${ }^{5}$ Além disso, elas se organizam segundo a divisão retórica referida no modelo histórico da ars dictaminis medieval, a arte de redigir documentos e cartas, compondo-se de exórdio, narração, argumentação e conclusão, subdividindo-se nas partes da disposição: saudação, captação da benevolência, narração, petição e conclusão e, seguindo, portanto, critérios bastante estritos de redação. ${ }^{6}$

Há que se considerar, assim, a importância dada pela Companhia de Jesus a seus documentos. Pode-se dizer que o funcionamento da instituição foi estabelecido sobre a produção de documentos e que a troca de informações e de instruções revela uma prática de poder fundada sobre a escrita. ${ }^{7}$ A correspondência exercia, assim, papel fundamental no governo e na administração da Ordem, evidenciando que não se tratava de textos "de autor", com liberdade de escrita, mas textos "de comando", compostos por dever de escritura da instituição jesuítica.

Ao lado dessa documentação administrativa - constituída por cartas entre Roma e as províncias, atas das Congregações provinciais, Catálogos e Ânuas - existia uma outra produção de textos que se caracterizava por uma dimensão de certa forma "pública" e "literária". Eram documentos destinados à circulação mais ampla, de escritura meticulosa, e que incluíam tratados descritivos dos povos, fauna e flora, narrativas de viagem, discursos históricos, as vidas, além das próprias cartas,

5 HANSEN, João Adolfo. Serafim Leite, História da Companhia de Jesus no Brasil. In: LOURENÇO, Dantas Mota (Org.). Introdução ao Brasil, Um banquete no trópico. São Paulo: Senac, 2001, p. 60.

6 PÉCORA, Alcir. Máquina de gêneros. São Paulo: Edusp, 2001, p. 18-23.

7 CASTELNAU-L'ESTOILE, Charlote de. Les ouvriers d'une vigne stérile: Les jésuits et la conversion des indiens au Brésil. 1580-1620. Lisboa/Paris: Fundação Calouste Gulbenkian/Comissão Nacional para as Comemoraçōes dos Descobrimentos Portugueses, 2000, p. 60-1. 
especialmente as Ânuas. Eram essas mesmas informações que serviam para fornecer matéria aos autores da própria Companhia que as utilizavam em suas obras de síntese, escritas em latim, destinadas a exaltar as conquistas portuguesas e, sobretudo, a fixar a imagem que a Companhia queria divulgar de si mesma.

Um exemplo desse tipo de documento, que pode mostrar-nos como funcionava o sistema de edição entre os jesuítas, é o manuscrito intitulado Cousas do Brasil, encontrado na Biblioteca de Évora, composto de diversos documentos encadernados juntos, todos datados dos anos 1550, em que se trata dos mais diversos assuntos: costumes e celebrações dos indígenas, clima da terra, informações sobre as capitanias e os aldeamentos, relato da missão do visitador Cristóvão Gouveia, discussões de questões doutrinais, cartas de Nóbrega e o "Diálogo sobre a conversão do gentio". A maior parte desses textos viria a aparecer mais tarde ligada à visitação de Gouveia à Colônia portuguesa, entre 1583 e 1589. O relato da visita foi assinado por Fernão Cardim, mas os tratados descritivos da fauna, da flora e do povo e as demais informações sobre a Colônia permaneceram anônimos, tendo Serafim Leite e Capistrano de Abreu atribuído a José de Anchieta a autoria de grande parte deles. ${ }^{8}$

Pode-se sugerir que esses tratados faziam parte das cartas previstas nas regras de escritura das Constituições e que, reunindo as informações, passavam a compor um "saber missionário coletivo". Com os dados coletados "pelos homens da terra ao cabo de suas experiências além-mar, em um dado momento, o da passagem de um visitador por exemplo, ocorre a cristalização desse saber informal sob a autoridade de um autor, habilitado pela instituição".9 Assim, o saber acumulado é posto sob forma determinada e, enviado às autoridades centrais a título de informação sobre a província, é feito circular sob determinada assinatura de autor. Dentro da elaboração desse saber missionário, o pertencimento à instituição era, portanto, mais importante que o status de autor, donde se tem que "a auctoritas é da instituição, não da pessoa". ${ }^{\circ}$

\footnotetext{
8 Ibidem, p. 370.

9 Ibidem, p. 376 (tradução nossa)

10 Ibidem, p. 376 (tradução nossa).
}

256 - CERELLO, Adriana Gabriel. Sobre o processo de edição dos textos jesuítas... 
Os processos de edição Examinando um outro nível do trabalho de edição, muito mais pormenorizado, pode-se observar a discussão sobre a autoria do texto das Constituições da Companhia de Jesus - o documento definidor de seu "poder executivo". O interesse é desvendar o processo de sua redação por meio dos diversos tipos de anotações encontrados nos documentos manuscritos que precederam a redação final do documento, compostos entre 1549 e 1553. Distinguidas por meio da caligrafia, essas notas demonstram o tipo de relação existente entre o secretário Juan Alfonso de Polanco e o próprio Inácio de Loyola, em um processo de escritura de documentos o qual, amplificado, pode fornecer indícios das práticas de edição realizadas nos demais textos jesuítas."

Polanco assumiu a função de secretário de Loyola apenas em março de 1547 , o que explica a sua pouca interferência nos primeiros escritos, saídos da pena do próprio Loyola e com anotações suas sobre eventuais consultas aos companheiros em estada romana. Esse fato é constatado a partir da observação de que Polanco várias vezes anota à margem ou em papel separado que não entende o significado de alguma palavra ou de alguma expressão, além de declarar sua isenção de haver estado na gênese desses documentos ao escrever: "Cuanto a estas Determinaciones, sería bien que me mostrasen las razones de donde se concluyen las conclusiones" ${ }^{12}$ Um dos primeiros trabalhos de Polanco ao assumir a secretaria da Ordem foi o de redigir as regras de seu ofício, cujo título era Del oficio del secretario que estará en Roma. Nesta Regra, define:

Para la invención y disposición [de las cosas que se escriben] etc., cuando fuere algo notado y ordenado por el superior, es menester seguirlo; pero, para entonces, y más cuando se comete del superior, $y$ tener entendidas y pensar con gran diligencia las cosas de la Compañía [...], y procurar de ver lo que cumple proveer [...]; pero desto, lo que se le representare, en cosas de importancia [...], propóngalo al superior, y siga su parecer. ${ }^{13}$

\footnotetext{
11 Tome-se como fonte ALDAMA, Antonio M. de, 5.J. La composición de las Constituciones de la Compañia de Jesús. In: Archivum Historicum Societatis lesu. [AHSI] 42. Roma, 1973, confiando em seu relato da manipulação que fez destes documentos, e lembrando ser ele também um padre jesuíta.

12 ALDAMA, Antonio M. de, S.J. Op. cit., p. 206-7.

13 Ibidem, p. 207.
} 
Com essa mesma diligência, Polanco entregou-se à correção e à redação das Constituições. Principiou estudando documentos pontifícios anteriores ao seu tempo e neles deixou assinalados os pontos que não entendia, os pontos em que tinha observações a fazer ou sugestões a acrescentar, detalhando tudo em índices e folhas de dúvidas. Buscou também as legislações de outras ordens religiosas, como as dos franciscanos, dominicanos e beneditinos, e anotou tudo que poderia vir a ter utilidade para o documento da Companhia. Desta pesquisa surgiu uma série de folhas de anotações conhecidas por Dúvidas, nas quais Polanco elenca observações e sugestões nascidas das leituras com o intuito de as submeter a Loyola. Deste processo de trabalho nasceu a mais antiga versão das Constituições. Segundo Aldama, das 145 páginas que compõem o códice, 109 estão escritas com a letra de Polanco. ${ }^{14}$ Assim, constata que o documento que serviu de base à redação das Constituições da Companhia de Jesus foi efetivamente redigido por Juan Alfonso de Polanco, sob comissão de Inácio de Loyola, um caso típico do trabalho secretarial da época.

Vê-se por meio das anotações a pesquisa e o exame de documentos realizados por Polanco, além de seu método de indagação e submissão aos ditames de Loyola, podendo-se mesmo usar a palavra "edição" para caracterizar a função do secretário na composição de tão importante documento.

Assim, a questão da autoria individualizada como propriedade particular era desconsiderada na Companhia de Jesus, tendo em vista os condicionamentos institucionais expostos. Levando-se em consideração esses critérios, pode-se dizer também que as cartas escritas pelos jesuítas no primeiro século da colonização não são efeito espontâneo nem da realidade dos índios nem da reação subjetiva dos padres. O discurso jesuítico é fruto do ajuste entre o costume retórico e a situação histórica.

De volta às cartas americanas, observam-se primeiramente as regras para escritura ditadas por Inácio de Loyola, separando matérias a serem tratadas em cartas diferentes e endereçadas a uns e não a outros. Quando do recebimento da correspondência na Europa, as cartas eram imediatamente traduzidas e corrigidas geralmente pelo secretário de quem se destinava a missiva, e pelo responsável de encaminhá-las a Roma. Lá, novamente traduzidas e corrigidas pelo secretário Polanco, elas eram

14 Ibidem, p. 212.

258 - CERELLO, Adriana Gabriel. Sobre o processo de edição dos textos jesuítas... 
efetivamente editadas e censuradas em um processo que envolvia desde correçōes ortográficas até grandes cortes, passando por alterações em que um termo substituído por vezes significava a aplicação de intenção moralizante ou de lição católica. Mostras disso são dadas pelo próprio Serafim Leite ao repetir a advertência, corrente entre os diversos padres organizadores da correspondência jesuítica, de que se deveria ler com desconfiança as cartas retocadas pelo padre Polanco, pois que ele agia muito livremente ao rever, emendar e cortar os textos. ${ }^{15}$

Chamar este processo "edição" a princípio parece bastante ingênuo, no entanto era esta mesma a origem não só das cartas exemplares que seguiriam para os diversos pontos de instalação da Companhia, como também das versões que se destinariam à impressão em coletâneas. Estas serviam, muitas vezes, para facilitar a distribuição dentro da própria Ordem, mas também para circular entre certo público leigo que passa a se interessar pelos assuntos ligados aos descobrimentos do começo do século Xvi.

Procurando exemplos desse processo de edição na correspondência dos padres da América, vemos na carta que António Pires escreveu de Pernambuco em 2 de agosto de 1551 para os irmãos de Coimbra, ${ }^{16}$ que a interferência do padre Polanco faz-se diretamente sobre o remetente da carta. Informa-nos Serafim Leite que, na tradução italiana que fez a partir da versão espanhola (pois alega que o original português está perdido), Polanco, além de emendas e cortes, omite o "autor" ao publicar o texto em Avisi Particolari delle Indie di Portugallo (1552), substituindo-o por "P. Nobrega cum socio"

Caso mais frequente é a substituição do destinatário original pelos "padres e irmãos" em geral, como na carta que Nóbrega escreveu de Pernambuco a Simão Rodrigues, provincial de Portugal, em 11 de agosto de $1551 .{ }^{17}$ Conforme anota Serafim Leite, na tradução espanhola feita do original português (perdido) já vemos os "Caríssimos Padres y Hermanos" endereçados; contudo, o texto da carta traz várias marcas do verdadeiro destinatário, assim: "Como Va. Ra. mandare

15 SERAFIM LEITE, S. J. Cartas dos primeiros jesuítas do Brasil. São Paulo: Comissão do IV Centenário, 1954, v. 1. p. 58.

16 Ibidem, carta 31, p. 250.

17 Ibidem, carta 33, p. 266 
quien sustente estotras partes", "los Padres que Va. Ra. embiare" e "quando Va. Ra. en esso no quisiere hablar" Neste caso, não podemos afirmar ser intervenção de Polanco, já que a edição que traz essa e outras cartas do mesmo período saiu no primeiro semestre de 1552, talvez antes do olho censor de Roma. No entanto, vêse que a "edição" era realizada em todas as esferas de leitura e não só nas instâncias superiores da Companhia de Jesus.

Este caso denota a transformação que sofriam estes textos, que passavam, assim, de cartas de informação a um superior hierárquico, a cartas de informação, de consolação ou de educação para todos, conforme sua intenção primeira, a utilidade aplicada ao reforço da unidade da Ordem como corpo místico. ${ }^{18}$

Também é esse o caso das traduções das orações e dos sermões feitos do português para o tupi, que tinham por finalidade não a troca entre iguais, mas o controle da "dispersão de línguas" e a imposição de "sua sintaxe e sua semântica". ${ }^{19}$ Conta o padre António Pires na mesma carta de 2 de agosto de 1551 para os irmãos de Coimbra, em parágrafos escritos ainda na Bahia, antes de partir para Pernambuco, que Nóbrega ordenara que o padre Azpilcueta fosse a Porto Seguro

a trasladar las oraciones y sermones en la lengua desta tierra, con algunos intérpretes que para esso avía muy buenos; las quales trasladó muy bien, y es mucho para dar alabanças al Señor viéndole predicar mucha parte del viejo testamento y nuevo, y otros sermones del juyzio, infierno, gloria, etc. ${ }^{20}$

Em nota, Serafim Leite nos informa que, segundo Capistrano de Abreu, ${ }^{21}$ o intérprete que auxiliou o padre Azpilcueta "na tradução das orações para a língua geral" foi Francisco Bruza de Espinosa. ${ }^{22}$ A confirmação da ajuda recebida encontrase na carta do padre Azpilcueta aos padres de Coimbra, escrita em Salvador por

18 HANSEN, João Adolfo. O Nu e a Luz: cartas jesuíticas do Brasil. Nóbrega, 1549-1558. In: Revista do Instituto de Estudos Brasileiros. no 38. Sảo Paulo: IEB-USP, 1995, p. 87-119.

19 NEVES, Luiz Felipe Baêta. O combate dos Soldados de Cristo na Terra dos Papagaios: Colonialismo e Repressão Cultural. Rio de Janeiro: Forense Universitária, 1978, p. 38.

20 SERAFIM LEITE, S. J. Op. cit., vol. I, carta 31, p. 252.

21 Ibidem, p. 278 (conforme Correspondência de Capistrano de Abreu, 1954).

22 Ibidem, carta 35, p. 278.

260 - CERELLO, Adriana Gabriel. Sobre o processo de edição dos textos jesuítas... 
volta de agosto de 1551, em que ele conta que "En esta Capitanía [Porto Seguro] hallé un hombre de buenas partes, antigo en la tierra, y tenía don de escrevir la lengua de los Indios, que fué para mi grande consolación" ${ }^{23} \mathrm{~A}$ crer no padre, vemos que não só o intérprete falava como também escrevia em tupi. Azpilcueta ainda acrescenta que "Todo lo mandaré en la primera embarcación" Era, portanto, o envio de material para a confecção de catecismos e dicionários na "língua geral" Segundo os critérios de autoria hoje vigentes, todos esses intérpretes, tradutores e padres missivistas teriam de ser considerados "autores". No entanto, naquela época e naquelas determinações institucionais, não era o que acontecia. Assim também o que hoje chamaríamos de "direitos autorais" não poderia existir na sua forma atual: ficavam a cargo de Roma a autorização para impressão e a seleção do material, além da já mencionada censura do mesmo.

As emendas de natureza ortográfica feitas às cartas dos padres jesuítas estavam normalmente relacionadas à mistura de português e castelhano em que se expressavam os ibéricos do século XVI, ou aos equívocos cometidos na escrita do latim. Na primeira carta de Manuel da Nóbrega, cuja impressão parece ter passado pelo crivo de Juan Alfonso de Polanco, vê-se pequena mostra desse tipo de interferência do padre em Roma. Serafim Leite mostra em seu aparato que na tradução da palavra "meninos" para o italiano, Polanco substituiu "putti" (lido na primeira versão da carta) por "fanciulli" pois soava "melhor a ouvidos ibéricos, como os de Polanco, que presidia a estas impressões".24 Em seguida, ao anotar a carta de João de Azpilcueta de março de 1550, Serafim Leite faz menção a um trecho que foi suprimido das traduções italianas realizadas a partir do original espanhol. Em dado momento, Azpilcueta, que foi o primeiro a aprender o tupi, refere-se à catequização dos meninos índios e diz que "el Pater Noster tiré en modo de sus cantares para que más presto aprendiesen y gustasen" ${ }^{25}$. Informa-nos Serafim Leite que, tendo o trecho sido suprimido da tradução italiana, também o foi das demais que se seguiram em outras línguas. ${ }^{26}$

\footnotetext{
23 Ibidem, carta 35, p. 279.

24 Ibidem, vol. I, carta 10, p. 155 (em 6 jan. 1550).

25 Ibidem, carta 14, p. 177 (em 28 mar. 1550).

26 Ibidem, p. 180, nota 6, linhas 55-6.
} 
Além desta, inúmeras outras emendas foram feitas ao texto, desde correções ortográficas e gramaticais até um trecho que conta dos índios comendo-se por ódio aos que estavam se entregando à conversão, passagem re-escrita pelo padre Polanco, segundo interpretação de Serafim Leite. Uma inocente inversão de ordem numa oração pode-nos indicar uma função muito maior e mais importante na estruturação destes textos antes de serem impressos ou mesmo traduzidos para serem distribuídos para o restante da Ordem. Assim, em dado momento, inverte a ordem do ensinar as orações aos mesmos meninos índios: o que era "en la suia lengua [tupi] como en la nuestra [português]" fica "en la nuestra lengua [português] como en la suia [tupi]"27

Um deslize do irmão Vicente Rodrigues (escrevendo da Bahia, em maio de 1552, por comissão do governador Tomé de Sousa ao padre Simão Rodrigues) é corrigido pelo padre Polanco. Irmão Vicente, no documento, narra o caso edificante de um pajé que se fingia de amigo dos padres; desmascarado, foi morto pelos indios. Escorregando no palavreado, escreve: "Tomó tanta passión el gentil que luego fué en busca del buen hombre y matáronle" O "buen hombre" seria, depois, substituído por "feiticeiro" porque um gentio, ainda mais trapaceiro, não podia ser ao mesmo tempo bom. Diante da narrativa de uma pequena indígena morrendo, que pede aos padres que orem por ela, Polanco suprime o trecho que dizia que os meninos índios também rezaram com os padres, provavelmente para evitar atribuir-se poder às orações de gentios, pois a menina curou-se pouco depois. Assim, onde se lia " $y$ haziendo los ninnos todos por ella oración, luego se alló bien" vê-se então " $y$ haziendo por ella oración, luego se alló bien" 28

Conclusão Por estes exemplos podemos ver indícios do trabalho efetuado sobre os textos produzidos pelos padres da Companhia de Jesus nas terras americanas. Vê-se aqui que as cartas produzidas na América eram enviadas para os mais diferentes destinatários e nem por isso deixavam de ser lidas, traduzidas e editadas por outros que as manipulavam como melhor convinha aos interesses de informar, de dar alento e de exemplificar aos demais dentro da Ordem.

27 Ibidem, p. 180, linha 54 (grifos nossos).

28 Cartas, vol. I, carta 44, p. 321.

262 • CERELLO, Adriana Gabriel. Sobre o processo de edição dos textos jesuítas... 
Escritas antes de as Constituições estarem totalmente definidas, estas cartas ainda traziam informações das cartas familiares mescladas às das negociais. Além da censura doutrinária que sofriam antes de circularem internamente, há que se lembrar ainda que esta mesma correspondência foi publicada em coletâneas destinadas a leitores leigos, geralmente movidos pela curiosidade "etnográfica" sobre o Novo Mundo. ${ }^{29}$

Adriana Gabriel Cerello é mestre em Literatura Brasileira pela Universidade de São Paulo. Foi bolsista da Fapesp.

29 HANSEN, João Adolfo (Org.). Introdução: Cartas de Antônio Vieira. In: Cartas do Brasil, Padre Antônio Vieira. São Paulo: Hedra, 2003, p. 19. 